\title{
Article \\ Preventive Effect of Canstatin against Ventricular Arrhythmia Induced by Ischemia/Reperfusion Injury: A Pilot Study
}

\author{
Akira Sugiyama, Yurie Shimizu, Muneyoshi Okada*D, Kosuke Otani and Hideyuki Yamawaki \\ Laboratory of Veterinary Pharmacology, School of Veterinary Medicine, Kitasato University, \\ Higashi 23 Bancho 35-1, Towada City, Aomori 034-8628, Japan; dv17003@st.kitasato-u.ac.jp (A.S.); \\ vm14065f@st.kitasato-u.ac.jp (Y.S.); otani@vmas.kitasato-u.ac.jp (K.O.); yamawaki@vmas.kitasato-u.ac.jp (H.Y.) \\ * Correspondence: mokada@vmas.kitasato-u.ac.jp; Tel.: +81-176-23-4371; Fax: +81-176-24-9456
}

Citation: Sugiyama, A.; Shimizu, Y.; Okada, M.; Otani, K.; Yamawaki, H. Preventive Effect of Canstatin against Ventricular Arrhythmia Induced by Ischemia/Reperfusion Injury: A Pilot Study. Int. J. Mol. Sci. 2021, 22, 1004. https://doi.org/10.3390/ijms22031004

Academic Editor: Terry Hébert

Received: 22 December 2020

Accepted: 18 January 2021

Published: 20 January 2021

Publisher's Note: MDPI stays neutral with regard to jurisdictional claims in published maps and institutional affiliations.

Copyright: (c) 2021 by the authors. Licensee MDPI, Basel, Switzerland. This article is an open access article distributed under the terms and conditions of the Creative Commons Attribution (CC BY) license (https:// creativecommons.org/licenses/by/ $4.0 /)$.

\begin{abstract}
Ventricular arrhythmia induced by ischemia/reperfusion (I/R) injury is a clinical problem in reperfusion therapies for acute myocardial infarction. $\mathrm{Ca}^{2+}$ overload through reactive oxygen species (ROS) production is a major cause for I/R-induced arrhythmia. We previously demonstrated that canstatin, a C-terminal fragment of type IV collagen $\alpha 2$ chain, regulated $\mathrm{Ca}^{2+}$ handling in rat heart. In this study, we aimed to clarify the effects of canstatin on I/R-induced ventricular arrhythmia in rats. Male Wistar rats were subjected to I/R injury by ligating the left anterior descending artery followed by reperfusion. Ventricular arrhythmia (ventricular tachycardia and ventricular fibrillation) was recorded by electrocardiogram. Nicotinamide adenine dinucleotide phosphate oxidase (NOX) activity and ROS production in neonatal rat cardiomyocytes (NRCMs) stimulated with oxygen glucose deprivation/reperfusion (OGD/R) were measured by lucigenin assay and $2^{\prime}, 7^{\prime}$ dichlorodihydrofluorescein diacetate staining, respectively. The $\mathrm{H}_{2} \mathrm{O}_{2}$-induced intracellular $\mathrm{Ca}^{2+}$ $\left(\left[\mathrm{Ca}^{2+}\right]_{\mathrm{i}}\right)$ rise in NRCMs was measured by a fluorescent $\mathrm{Ca}^{2+}$ indicator. Canstatin $(20 \mu \mathrm{g} / \mathrm{kg})$ inhibited $\mathrm{I} / \mathrm{R}$-induced ventricular arrhythmia in rats. Canstatin $(250 \mathrm{ng} / \mathrm{mL})$ inhibited OGD/R-induced NOX activation and ROS production and suppressed the $\mathrm{H}_{2} \mathrm{O}_{2}$-induced $\left[\mathrm{Ca}^{2+}\right]_{i}$ rise in NRCMs. We for the first time demonstrated that canstatin exerts a preventive effect against I/R-induced ventricular arrhythmia, perhaps in part through the suppression of ROS production and the subsequent $\left[\mathrm{Ca}^{2+}\right]_{i}$ rise.
\end{abstract}

Keywords: arrhythmia; calcium overload; canstatin; ischemia/reperfusion; reactive oxygen species

\section{Introduction}

Myocardial infarction (MI) is caused by a coronary thrombosis mainly due to the disruption of atherosclerotic plaque [1]. Reperfusion therapies, such as percutaneous coronary intervention and thrombolytic therapy, are established as the most effective therapies for acute MI (AMI) [2]. However, ischemia/reperfusion (I/R) injury, a critical complication of the therapies, is a serious clinical problem associated with a high mortality [3,4]. More than $80 \%$ of AMI patients develop arrhythmia, including lethal ventricular tachycardia (VT) and ventricular fibrillation (VF), during the first $48 \mathrm{~h}$ after reperfusion [4]. However, there is no effective strategy for preventing I/R injury and subsequent arrhythmia [2].

$\mathrm{I} / \mathrm{R}$ injury induces reactive oxygen species (ROS) production, which causes $\mathrm{Ca}^{2+}$ overload via increasing intracellular $\mathrm{Ca}^{2+}\left(\left[\mathrm{Ca}^{2+}\right]_{i}\right)$ through the regulation of $\mathrm{Ca}^{2+}$ handling proteins, such as L-type $\mathrm{Ca}^{2+}$ channel (LTCC), $\mathrm{Na}^{+}-\mathrm{Ca}^{2+}$ exchanger (NCX), ryanodine receptor (RyR) and sarcoplasmic reticulum $\mathrm{Ca}^{2+}$-ATPase (SERCA), in cardiomyocytes $[5,6]$. The $\mathrm{Ca}^{2+}$ overload leads to early afterdepolarizations (EADs) and delayed afterdepolarizations (DADs), which trigger ventricular arrhythmia [6-8]. Verapamil, a non-dihydropyridine $\mathrm{Ca}^{2+}$ channel blocker, is widely used as a Vaughan Williams class IV anti-arrhythmic drug [9]. However, the usefulness of the $\mathrm{Ca}^{2+}$ channel blockers for the early treatment of AMI is still under discussion, since adverse events have been reported, including the worsening of heart failure $[9,10]$. 
Canstatin, a C-terminal fragment of the type IV collagen $\alpha 2$ chain, was originally discovered as an endogenous anti-angiogenic and anti-tumor factor [11]. Canstatin is abundantly expressed in normal rat hearts, the expression of which is decreased in the infarcted area after MI $[12,13]$. We previously reported that a knockdown of canstatin by injecting a small interference (si)RNA of type IV collagen $\alpha 2$ chain gene (COL4A2) in rats induced changes in electrocardiogram (ECG) parameters, such as the shortening of the QT interval and the increasing of the T wave amplitude [14]. Furthermore, in ventricular myocytes from the COL4A2 siRNA-injected rats, LTCC current was increased, which was reversed by an exogenous canstatin [14]. We also demonstrated that canstatin inhibited the isoproterenol-induced $\left[\mathrm{Ca}^{2+}\right]_{i}$ rise in neonatal rat cardiomyocytes (NRCMs) [15]. Thus, it is suggested that canstatin regulates $\mathrm{Ca}^{2+}$ handling in rat heart.

In the present study, we hypothesized that canstatin suppresses ventricular arrhythmia by inhibiting the $\mathrm{Ca}^{2+}$ overload induced by I/R injury. To test this hypothesis, we investigated the effects of canstatin on I/R-induced ventricular arrhythmia using an in vivo model of I/R-induced ventricular arrhythmia. We also examined the detailed mechanisms of the effect of canstatin using an in vitro model of I/R injury in NRCMs.

\section{Results}

\subsection{Canstatin Inhibited I/R-Induced Ventricular Arrhythmia}

We first examined the effect of canstatin on I/R-induced ventricular arrhythmia in rats (Figures 1 and 2). We confirmed that all rats showed a sinus rhythm during pre-ischemia (Figure 2A) and a significant ST elevation during ischemia (Figure 2A). In all phosphate buffered saline (PBS)-administered rats, VT and VF were observed during reperfusion (Figure 2A). Although VT was observed in $80 \%(4 / 5)$ of canstatin-administered rats, VF was not observed (Figure 2A). In verapamil-administered rats, only premature ventricular contraction was observed (Figure 2A). A quantitative analysis for ventricular arrhythmia (VT and VF) showed that canstatin had no effect on incidence (PBS: $3.6 \pm 0.9$ times vs. canstatin: $3.6 \pm 1.8 \times, n=5$ ), but significantly inhibited the total and average durations of ventricular arrhythmia (total duration-canstatin: $10.5 \pm 3.4 \mathrm{~s}$ vs. PBS: $60.7 \pm 16.9 \mathrm{~s}$, $p<0.05$; average duration-canstatin: $4.2 \pm 2.0$ s vs. PBS: $18.2 \pm 3.0 \mathrm{~s}, p<0.01, n=5$ ) (Figure $2 \mathrm{~B}$ ). Verapamil completely suppressed the incidence and duration of ventricular arrhythmia $(n=3)$ (data not shown).

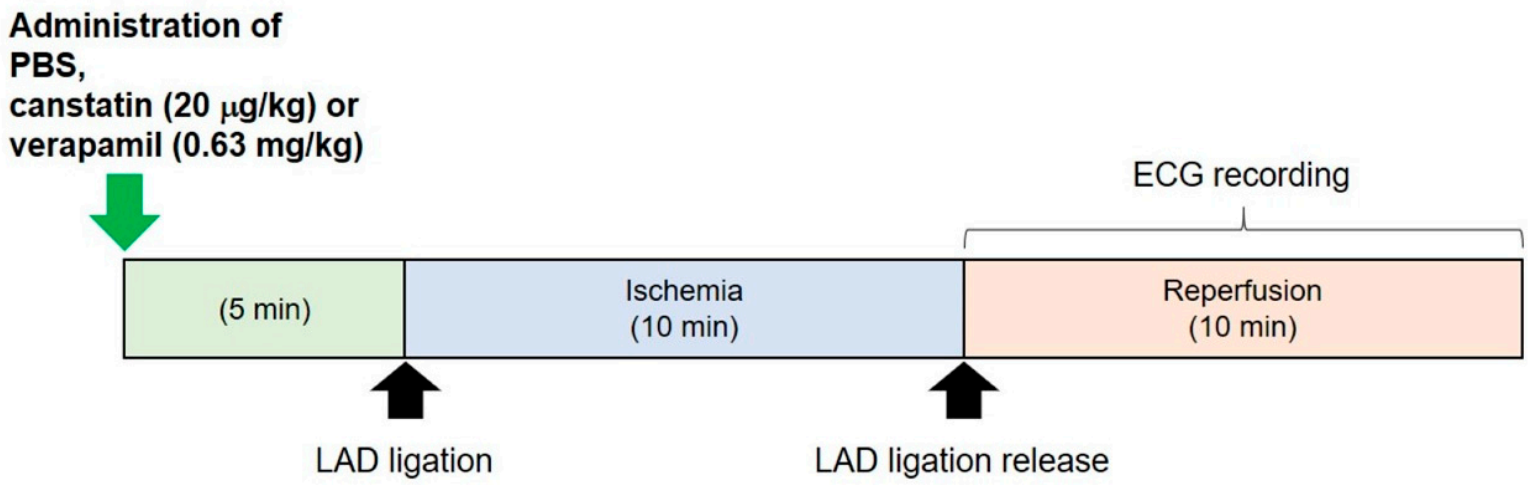

Figure 1. Protocol for the in vivo study of ischemia/reperfusion (I/R)-induced ventricular arrhythmia. Phosphate buffered saline (PBS), canstatin $(20 \mu \mathrm{g} / \mathrm{kg})$ or verapamil $(0.63 \mathrm{mg} / \mathrm{kg})$ was intravenously administered to rats. Five minutes after the administration, left anterior descending artery (LAD) ligation was performed (ischemia). Ten minutes after the ligation, it was released (reperfusion). An electrocardiogram (ECG) recording was performed for 10 min after reperfusion. 
A

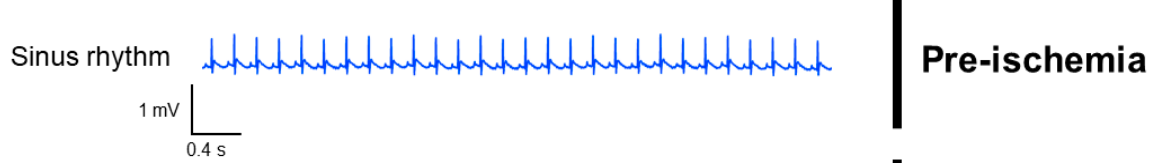

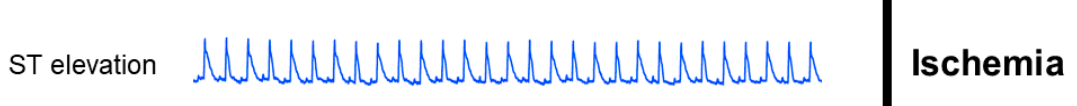

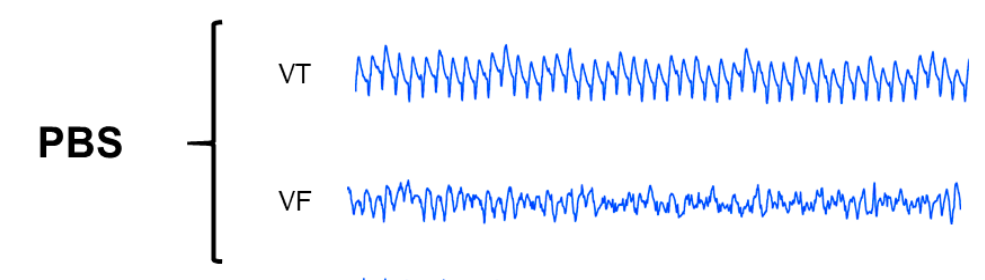
Canstatin

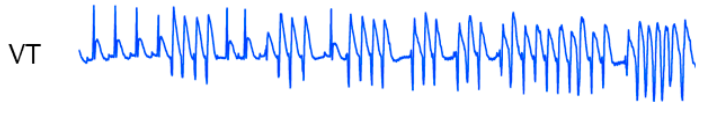

Reperfusion Verapamil

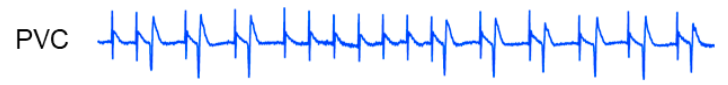

\section{B}

Incidence

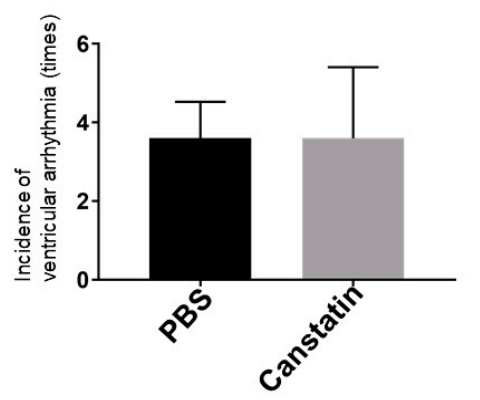

$\underline{\text { Total duration }}$

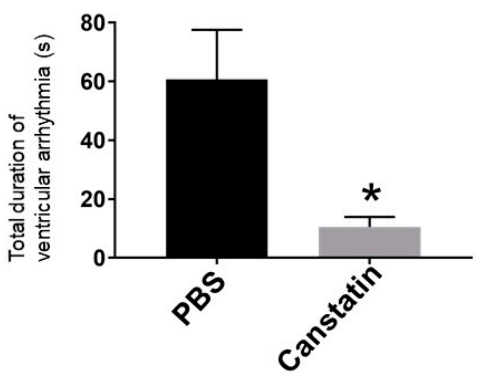

Average duration

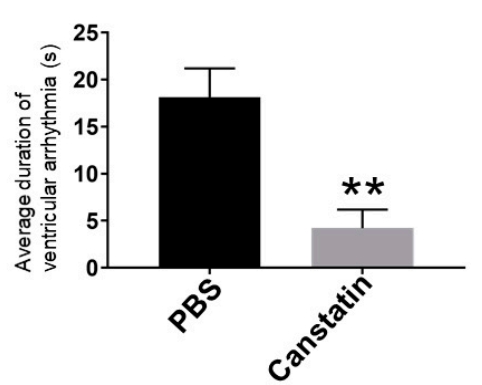

Figure 2. Canstatin inhibited I/R-induced ventricular arrhythmia. PBS, canstatin $(20 \mu \mathrm{g} / \mathrm{kg})$ or verapamil $(0.63 \mathrm{mg} / \mathrm{kg})$ was intravenously administered to rats. Five minutes after the administration, I/R injury was induced by ligating LAD for $10 \mathrm{~min}$ (ischemia) followed by releasing it (reperfusion). ECG (lead II) was recorded throughout the experiments. (A) Representative ECG tracings of sinus rhythm during pre-ischemia, ST elevation during ischemia and arrhythmias in PBS-, canstatin- and verapamil-administered rats during reperfusion were shown. VT: ventricular tachycardia, VF: ventricular fibrillation, PVC: premature ventricular contraction. (B) Incidence (left), total duration (middle) and average duration (right) of ventricular arrhythmia (VT and VF) for $10 \mathrm{~min}$ after reperfusion were calculated from the ECG tracings and shown as mean \pm standard error of the mean (S.E.M.) ((A): PBS, Canstatin: $n=5$, Verapamil: $n=3,(\mathbf{B}): n=5)$. $*$ ** $p<0.05,0.01$ vs. PBS.

2.2. Canstatin Inhibited Oxygen and Glucose Deprivation Followed by Reoxygenation (OGD/R)-Induced Nicotinamide Adenine Dinucleotide Phosphate (NADPH) Oxidase (NOX) Activation in NRCMs

To investigate the detailed mechanisms of the protective effects of canstatin against I/R-induced ventricular arrhythmia, OGD/R stimulation, which mimics I/R injury in vitro, was performed in NRCMs (Figure 3). I/R injury is known to activate NOX, a major source for ROS production, in myocardium [5]. Thus, a lucigenin assay was performed to examine the effect of canstatin on OGD/R-induced NOX activation in NRCMs. OGD/R significantly induced NOX activation ( $144.2 \pm 4.0 \%, p<0.05$ vs. Cont (Figure 3 Upper), $n=6$ ), which was 
significantly inhibited by canstatin $(105.6 \pm 17.7 \%, p<0.05$ vs. OGD/R, $n=6)$ (Figure $4 \mathrm{~A})$. We confirmed that both gp91 ds-tat $(2.5 \mu \mathrm{M})$, an inhibitor of NOX, and tempol $(1 \mathrm{mM})$, an antioxidant, significantly inhibited the OGD/R-induced NOX activation (gp91 ds-tat: $96.4 \pm 5.8 \%$; tempol: $89.6 \pm 4.0 \%, p<0.01$ vs. OGD/R, $n=4$ ) (Figure 4B).

\begin{tabular}{|c|c|}
\cline { 2 - 3 } Cont $\begin{array}{c}\text { Normoxia+ } \\
\text { High glucose DMEM } \\
(24 \mathrm{~h})\end{array}$ & $\begin{array}{c}\text { Normoxia+High glucose DMEM } \\
(15 \mathrm{~min})\end{array}$ \\
\cline { 2 - 3 } & PBS \\
\hline
\end{tabular}

\begin{tabular}{|c|c|c|c|}
\hline \multirow{2}{*}{ OGD/R } & \multirow{2}{*}{$\begin{array}{c}\text { Normoxia+ } \\
\text { High glucose DMEM } \\
(24 \mathrm{~h})\end{array}$} & $\begin{array}{l}\text { Hypoxia+Glucose-free DMEM } \\
\text { (10 min) }\end{array}$ & $\begin{array}{l}\text { Normoxia+High glucose DMEM } \\
\qquad(5 \mathrm{~min})\end{array}$ \\
\hline & & \multicolumn{2}{|c|}{ PBS } \\
\hline
\end{tabular}

\begin{tabular}{l|c|c|c|}
\cline { 2 - 3 } $\begin{array}{l}\text { +canstatin } \\
\text { +gp91 ds-tat } \\
\text { +tempol }\end{array}$ & $\begin{array}{c}\text { Normoxia+ } \\
\text { High glucose DMEM } \\
(24 \mathrm{~h})\end{array}$ & $\begin{array}{c}\text { Hypoxia+Glucose-free DMEM } \\
(10 \mathrm{~min})\end{array}$ & $\begin{array}{c}\text { Normoxia+High glucose DMEM } \\
(5 \mathrm{~min})\end{array}$ \\
\cline { 2 - 3 } & & Canstatin $(250 \mathrm{ng} / \mathrm{ml})$, gp91 ds-tat $(2.5 \mu \mathrm{M})$ or tempol (1 mM $)$ \\
\cline { 2 - 3 }
\end{tabular}

Figure 3. Protocols for oxygen glucose deprivation/reperfusion (OGD/R) stimulation in neonatal rat cardiomyocytes (NRCMs). NRCMs were starved for $24 \mathrm{~h}$ in serum-free high-glucose-containing Dulbecco's modified Eagle's medium (DMEM) before the experiment. ((Upper): Cont) The cells were cultured in high-glucose-containing DMEM under normoxic conditions $\left(95 \%\right.$ air and $5 \% \mathrm{CO}_{2}$ at $\left.37^{\circ} \mathrm{C}\right)$ for $15 \mathrm{~min}$. In order to follow the condition of OGD/R stimulation, medium change was performed at $10 \mathrm{~min}$. PBS, a vehicle, was treated throughout the experiment. ((Middle): OGD/R) The cells were cultured in glucose-free DMEM under hypoxic conditions $\left(1 \% \mathrm{O}_{2}, 94 \% \mathrm{~N}_{2}\right.$ and $5 \% \mathrm{CO}_{2}$ at $\left.37^{\circ} \mathrm{C}\right)$ for $10 \mathrm{~min}(\mathrm{OGD})$. Then, the cells were cultured with high-glucose-containing DMEM in normoxic conditions for 5 min (R). PBS was treated throughout the experiment. (Lower) The cells were stimulated with OGD/R. Canstatin (+canstatin: $250 \mathrm{ng} / \mathrm{mL}$ ), gp91 ds-tat (+gp91 ds-tat: $2.5 \mu \mathrm{M})$ or tempol (+tempol: $1 \mathrm{mM})$ was treated throughout the experiment.

A

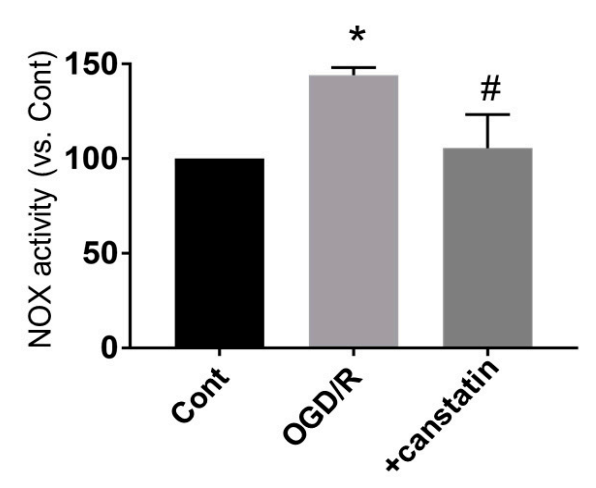

B

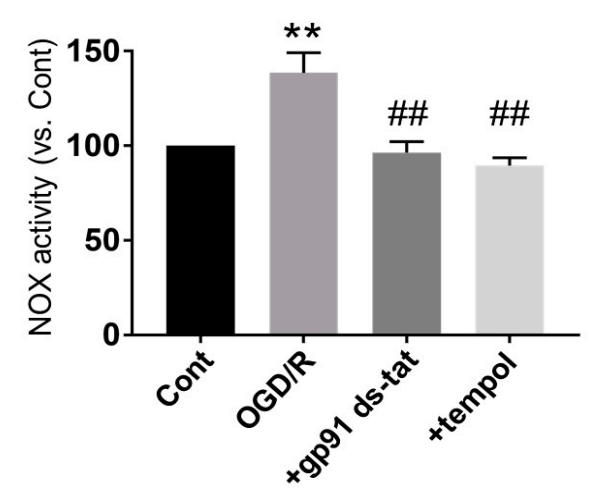

Figure 4. Canstatin inhibited the OGD/R-induced activation of nicotinamide adenine dinucleotide phosphate (NADPH) oxidase (NOX) in NRCMs. NRCMs were stimulated with OGD/R (see the protocols described in Figure 3). Control cells were cultured in the reperfusion medium under normoxic conditions (Cont; (A,B)). PBS (Cont, OGD/R; (A,B)), canstatin (+canstatin: $250 \mathrm{ng} / \mathrm{mL}$; (A)), gp91 ds-tat (+gp91 ds-tat: $2.5 \mu \mathrm{M}$; (B)) or tempol (+tempol: $1 \mathrm{mM}$; (B)) was treated throughout the OGD/R stimulation. Total cell lysates of the NRCMs were harvested and NOX activity was determined by lucigenin assay. The normalized NOX activity relative to PBS was shown as mean \pm S.E.M. ((A): $n=6,(\mathbf{B}): n=4) .{ }^{*},{ }^{* *} p<0.05,0.01$ vs. Cont, \#, \#\# $p<0.05,0.01$ vs. OGD/R.

\subsection{Canstatin Inhibited OGD/R-Induced ROS Production in NRCMs}

ROS production is closely associated with I/R-induced arrhythmia [16]. Thus, 2', 7'dichlorodihydrofluorescein diacetate (DCF-DA) staining was performed to examine the 
effect of canstatin on OGD/R-induced ROS production in NRCMs. OGD/R significantly induced ROS production ( $784.5 \pm 156.3 \%, p<0.01$ vs. Cont, $n=6)$, which was significantly inhibited by canstatin ( $155.4 \pm 30.1 \%, p<0.01$ vs. OGD/R, $n=6)$ (Figure 5).

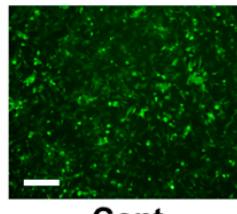

Cont

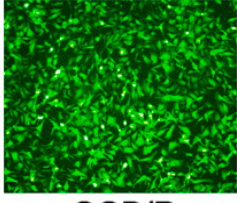

OGD/R

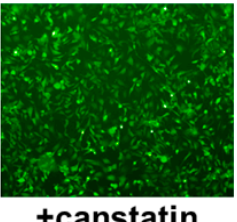

+canstatin

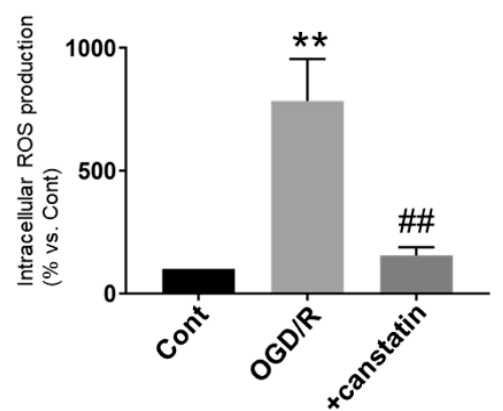

Figure 5. Canstatin inhibited OGD/R-induced reactive oxygen species (ROS) production in NRCMs. NRCMs were stimulated with OGD/R (see the protocols described in Figure 3). Control cells were cultured in the reperfusion medium under normoxic condition (Cont). PBS (Cont, OGD/R) or canstatin (+canstatin: $250 \mathrm{ng} / \mathrm{mL}$ ) was treated throughout the OGD/R stimulation. The cells were treated with $2^{\prime}, 7^{\prime}$-dichlorodihydrofluorescein diacetate (DCF-DA; $10 \mu \mathrm{M}$ ) for $30 \mathrm{~min}$ to detect intracellular ROS production. (Upper) Representative images for DCF-DA-stained cells were shown. Scale bar: $100 \mu \mathrm{m}$. (Lower) The normalized fluorescent intensity of DCF-DA relative to PBS was shown as mean \pm S.E.M. $(n=6) .{ }^{* *} p<0.01$ vs. Cont, \#\# $p<0.01$ vs. OGD $/$ R.

\subsection{Canstatin Inhibited $\mathrm{H}_{2} \mathrm{O}_{2}$-Induced $\left[\mathrm{Ca}^{2+}\right]_{i}$ Rise in NRCMs}

The ROS-induced $\left[\mathrm{Ca}^{2+}\right]_{\mathrm{i}}$ rise in cardiomyocytes leads to ventricular arrhythmias [16]. Thus, we investigated the effect of canstatin on $\left[\mathrm{Ca}^{2+}\right]_{\mathrm{i}}$ increase induced by $\mathrm{H}_{2} \mathrm{O}_{2}(100 \mu \mathrm{M})$ in NRCMs. $\mathrm{H}_{2} \mathrm{O}_{2}$ induced a $\left[\mathrm{Ca}^{2+}\right]_{\mathrm{i}}$ rise $(0.107 \pm 0.009)$, which was significantly inhibited by canstatin $(0.079 \pm 0.010, p<0.05$ vs. Cont, $n=9)$ (Figure $6 \mathrm{~A}, \mathrm{~B})$. Tempol also significantly inhibited the $\mathrm{H}_{2} \mathrm{O}_{2}$-induced $\left[\mathrm{Ca}^{2+}\right]_{\mathrm{i}}$ rise $(0.061 \pm 0.008, p<0.01$ vs. Cont, $n=7)$ (Figure 6A,B).
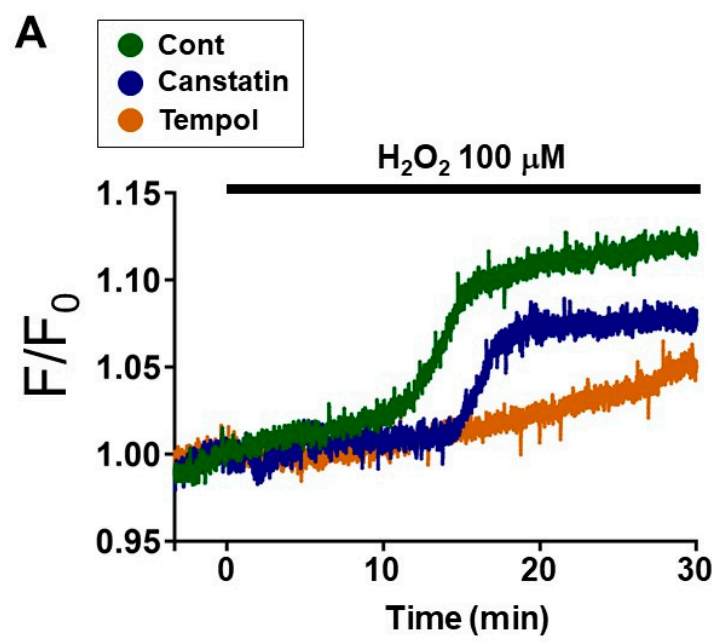

B

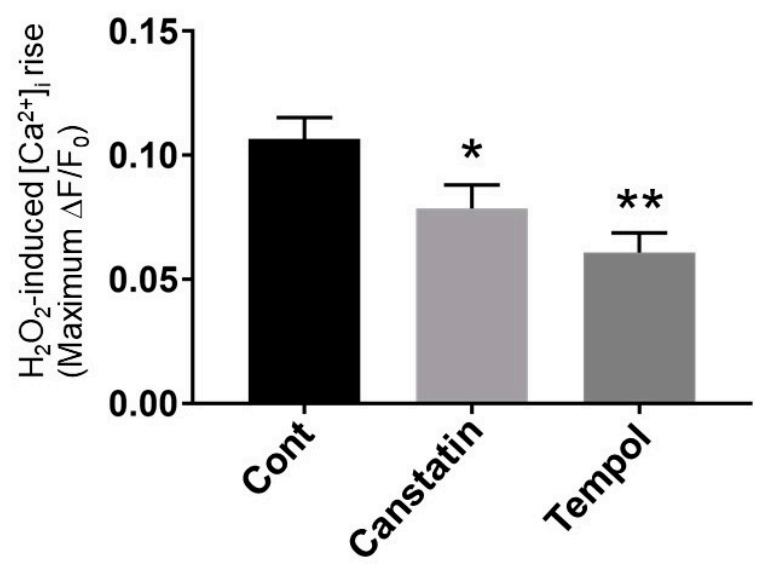

Figure 6. Canstatin inhibited $\mathrm{H}_{2} \mathrm{O}_{2}$-induced intracellular $\mathrm{Ca}^{2+}\left(\left[\mathrm{Ca}^{2+}\right]_{\mathrm{i}}\right)$ rise in NRCMs. NRCMs were stimulated with $\mathrm{H}_{2} \mathrm{O}_{2}(100 \mu \mathrm{M})$ for $30 \mathrm{~min}$ following $10 \mathrm{~min}$ pre-treatment with PBS, canstatin $(250 \mathrm{ng} / \mathrm{mL})$ or tempol $(1 \mathrm{mM})$. [Ca $\left.{ }^{2+}\right]_{\mathrm{i}}$ rise 
was measured by using Fura-2 acetoxymethyl ester, a fluorescent $\mathrm{Ca}^{2+}$ indicator. The F340/F380 ratio (F) was calculated and normalized by the basal fluorescence $\left(\mathrm{F}_{0}\right)$ at $30 \mathrm{~s}$ before $\mathrm{H}_{2} \mathrm{O}_{2}$ stimulation $\left(\mathrm{F} / \mathrm{F}_{0}\right)$. (A) Representative time course of $\mathrm{F} / \mathrm{F}_{0}$ for $30 \mathrm{~min}$ in NRCMs stimulated with $\mathrm{H}_{2} \mathrm{O}_{2}$ in the presence of PBS (Cont: Green), canstatin (Blue) or tempol (Brown) was shown. The fluorescence was recorded every $0.1 \mathrm{~s}$. (B) The maximum $F / \mathrm{F}_{0}$ change $\left(\Delta \mathrm{F} / \mathrm{F}_{0}\right)$ caused by $\mathrm{H}_{2} \mathrm{O}_{2}$-induced $\left[\mathrm{Ca}^{2+}\right]_{\mathrm{i}}$ rise was shown as mean \pm S.E.M. (Cont, Canstatin: $n=9$; tempol: $\left.n=7\right)$. ${ }^{*}{ }^{* *} p<0.05,0.01$ vs. Cont.

\section{Discussion}

In the present study, we for the first time demonstrated that canstatin suppressed I/R-induced ventricular arrhythmia in rats. Furthermore, canstatin inhibited OGD/Rinduced NOX activation and ROS production, and suppressed the $\mathrm{H}_{2} \mathrm{O}_{2}$-induced $\left[\mathrm{Ca}^{2+}\right]_{i}$ rise in NRCMs.

ST elevation is a characteristic waveform observed during ischemia in a rat model of I/R-induced ventricular arrhythmia [17]. In this study, ST elevation by left anterior descending artery (LAD) ligation was confirmed in all rats (Figure 2A). In PBS-administered rats, VT and VF were observed during reperfusion similarly to the previous studies $[18,19]$. Thus, we successfully made an in vivo model of I/R-induced ventricular arrhythmia. In the present study, canstatin suppressed the occurrence of VF and inhibited the duration of ventricular arrhythmia after reperfusion (Figure 2). NOX is a major source for ROS production in the I/R-injured heart [5]. The ROS mainly contribute to I/R injury [4,5] through the mechanisms including $\mathrm{Ca}^{2+}$ overload, which leads to ventricular arrhythmia [20]. In this study, canstatin significantly inhibited the OGD/R-induced NOX activation and ROS production in NRCMs (Figures 4 and 5). Thus, it is suggested that canstatin exerts an anti-arrhythmic effect against I/R stimulation perhaps in part through the inhibition of NOX-induced ROS production and $\left[\mathrm{Ca}^{2+}\right]_{i}$ rise.

The anti-angiogenic and anti-tumor effects of canstatin were mediated through its binding to $\alpha_{\mathrm{v}} \beta_{3}$ and $\alpha_{\mathrm{v}} \beta_{5}$ integrins [21]. It has been reported that integrins were associated with NOX activation and ROS production [22,23], and that type IV collagen mediated the activation of NOX1 through their binding to $\alpha_{2} \beta_{1}$ integrin in the human adenocarcinoma cell line [22]. The ectodomain of syndecan-4, a heparan sulfate proteoglycan, induced ROS production through the binding to $\alpha_{v} \beta_{3}$ integrin in mouse podocytes [23]. On the other hand, the expression of integrins on the cell membrane was increased by an ischemic stimulation [24,25]. We previously demonstrated that hypoxia induced the recruitment of the $\alpha_{\mathrm{v}}$ integrin to the focal adhesion of the cell membrane [26], and that canstatin activated the focal adhesion of kinase/Akt signaling under the hypoxic condition in H9c2 cardiomyoblasts [26]. Thus, it is presumed that the inhibitory effects of canstatin against NOX activation and ROS production might be caused by their binding to integrins.

ROS induce the $\left[\mathrm{Ca}^{2+}\right]_{\mathrm{i}}$ rise through the activation of $\mathrm{Ca}^{2+}$ handling proteins, such as LTCC, NCX and RyR [6]. In the present study, we demonstrated that canstatin inhibited the $\mathrm{H}_{2} \mathrm{O}_{2}$-induced $\left[\mathrm{Ca}^{2+}\right]_{i}$ rise in NRCMs (Figure 6). We previously reported that the LTCC current was increased in ventricular myocytes from the COL4A2 siRNA-injected rats, which was reversed by canstatin [14]. In addition, canstatin inhibited the isoproterenol-induced $\left[\mathrm{Ca}^{2+}\right]_{\mathrm{i}}$ rise in NRCMs [15]. Thus, it is suggested that canstatin inhibits the ROS-induced $\left[\mathrm{Ca}^{2+}\right]_{\mathrm{i}}$ rise by regulating intracellular $\mathrm{Ca}^{2+}$ handling. Wu et al. demonstrated that soluble ligands of $\alpha_{\mathrm{v}} \beta_{3}$ integrin inhibited the LTCC current in rat arteriolar smooth muscle cells [27]. Furthermore, $\beta_{1}$ integrin colocalized with RyR in T-tubules protected I/R injury in mouse cardiomyocytes by regulating intracellular $\mathrm{Ca}^{2+}$ handling [28]. Thus, it is presumed that canstatin inhibits the ROS-induced activation of $\mathrm{Ca}^{2+}$ handling proteins through their binding to integrins.

Verapamil, which was used as a positive control in this study, completely blocked the $\mathrm{I} / \mathrm{R}$-induced ventricular arrhythmia in rats (Figure 2A). Although $\mathrm{Ca}^{2+}$ channel blockers, including verapamil, are clinically used for the treatment of supraventricular arrhythmias [29], the adverse events, including the worsening of heart failure, have been indicated [9]. It is predicted that canstatin hardly exerts side effects since it is an endogenous 
peptide abundantly expressed in normal hearts [12]. We previously reported that the long-term administration of canstatin $(20 \mu \mathrm{g} / \mathrm{kg} /$ day, 28 days, i.p.) had no effect on cardiac function in normal rats $[15,30]$. In addition, we recently demonstrated that the administration of canstatin $(20 \mu \mathrm{g} / \mathrm{kg} /$ day, 28 days, i.p.) improved survival rate and cardiac dysfunction in MI model rats [30]. Thus, it is suggested that canstatin might exert an anti-arrhythmic effect without exaggerating cardiac dysfunction after MI.

There are limitations to the present study. First, canstatin was administered to rats before I/R injury. However, in AMI patients receiving percutaneous coronary intervention, drug administration is performed at the time of reperfusion. Thus, we should investigate the anti-arrhythmic effects of canstatin at the time of reperfusion to mimic the clinical scenario in a future study. Second, the duration of ischemia protocol in both in vivo and in vitro experimental studies was short, which was sub-lethal. Thus, our results are not able to directly extrapolate into a typical human AMI, which leads to severe cardiomyocyte death and infarction. Thus, we should investigate whether canstatin exerts anti-arrhythmic effects by using an alternative experimental model that is more relevant to the clinical scenario in a future study.

\section{Materials and Methods}

\subsection{Regents}

The reagent sources were as follows: recombinant mouse canstatin (produced by Escherichia coli as described previously [15]), verapamil and tempol (Sigma-Aldrich, St. Louis, $\mathrm{MO}, \mathrm{USA}$ ), gp91 ds-tat (Eurogentec, Seraing, Belgium) and $\mathrm{H}_{2} \mathrm{O}_{2}$ (Kanto Chemical, Tokyo, Japan). PBS ( $\mathrm{NaCl} 137 \mathrm{mM}, \mathrm{KCl} 2.7 \mathrm{mM}, \mathrm{Na}_{2} \mathrm{HPO}_{4} 10 \mathrm{mM}, \mathrm{KH}_{2} \mathrm{PO}_{4} 1.8 \mathrm{mM}, \mathrm{pH}$ 7.4) was used as a vehicle for recombinant canstatin.

\subsection{Animals}

All animal experiments were approved by the President of Kitasato University through the judgement of Institutional Animal Care and Use Committee of Kitasato University (Approval No. 18-019 (18 June 2018), 19-126 (29 August 2019)). Male Wistar rats (CLEA Japan, Tokyo, Japan) were cared in accordance with the guideline for animal care and treatment of the Kitasato University. For the production of an in vivo model of I/Rinduced ventricular arrhythmia and the isolation of NRCMs, 10-week-old and 1-3-day-old rats were used, respectively.

\subsection{In Vivo Model of I/R-Induced Ventricular Arrhythmia}

Ten-week-old rats $(n=13)$ were anesthetized with urethane $(1.4 \mathrm{~g} / \mathrm{kg}$, i.p.). Then, the rats were artificially ventilated (respiratory rate: 80 times/min; tidal volume: $5 \mathrm{~mL}$; SN-480-7; Shinano, Tokyo, Japan) following an endotracheal intubation, and intravenous cannulation to the saphenous vein was performed for the administration of drugs. After a left thoracotomy was performed, 3 Spring Clip Electrodes (MLA1210; AD Instruments, Colorado Springs, CO, USA) connected to a 3-Lead Shielded Bio Amp Cable (MLA2340; AD Instruments) were fixed on the right axillary (cathode), left pectoral (anode) and right inguinal (earth) regions. ECG recording was performed by using a Bio Amp (FE132; AD Instruments) and PowerLab system (ML825; AD Instruments) in lead II configuration. A 6-0 nylon suture was passed under LAD. The suture was threaded through a polyethylene tube to create a snare. Recombinant canstatin $(20 \mu \mathrm{g} / \mathrm{kg}, n=5)$, PBS $(n=5)$ or verapamil $(0.63 \mathrm{mg} / \mathrm{kg}, n=3)$ was intravenously administered for $5 \mathrm{~min}$. Verapamil was used as a positive control. Then, LAD ligation was performed by tightening the snare (ischemia). Ten minutes after the ligation, it was released (reperfusion). VT and VF were recorded for 10 min after reperfusion (Figure 1). The incidence and duration of ventricular arrhythmia during the recording were calculated. 


\subsection{Isolation of NRCMs}

NRCMs were isolated from neonatal Wistar rats as described previously [15]. The hearts harvested from 1-3-day-old Wistar rats were washed in PBS with $20 \mathrm{mM}$ 2,3butanedione monoxime (BDM) on ice. Then, the ventricles of the hearts were minced into small pieces and washed in wash solution (Hank's Balanced Salt Solution with $0.08 \%$ trypsin and $20 \mathrm{mM} \mathrm{BDM}$ ) for $2 \mathrm{~h}$ at $4{ }^{\circ} \mathrm{C}$ with stirring followed by an incubation in collagenase solution (Leibovitz's L15 medium with $0.15 \%$ collagenase and $20 \mathrm{mM} \mathrm{BDM}$ ) for $30 \mathrm{~min}$ at $37^{\circ} \mathrm{C}$. The suspension, tissue fragments of which were removed by filtration, was centrifuged at $100 \times \mathrm{g}$ for $5 \mathrm{~min}$ at $4{ }^{\circ} \mathrm{C}$, and the pellet was resuspended in highglucose Dulbecco's modified Eagle medium (DMEM; Wako, Osaka, Japan) containing 10\% feral bovine serum (FBS; Gibco/Lifetechnologies, Carlsbad, CA, USA), 1\% antibioticantimycotic mixed solution (Nacalai tesque, Kyoto, Japan) and $100 \mu \mathrm{M}$ bromodeoxyuridine (BrdU). The cell suspension was pre-plated for $90 \mathrm{~min}$ twice to remove the attached noncardiomyocytes. The non-attached cardiomyocytes were collected, seeded and cultured on culture dishes (for lucigenin assay) or coverslips coated with $1 \%$ gelatin (for DCFDA staining or measurement of $\left[\mathrm{Ca}^{2+}\right]_{\mathrm{i}}$ ) in high-glucose DMEM containing $10 \% \mathrm{FBS}, 1 \%$ antibiotic-antimycotic mixed solution and $100 \mu \mathrm{M}$ BrdU.

\section{5. $O G D / R$}

To mimic I/R injury, OGD/R was performed in NRCMs as described previously [31] (Figure 3). After NRCMs at subconfluence were starved for $24 \mathrm{~h}$ in serum-free high-glucose DMEM, the culture medium was replaced with glucose-free DMEM (Wako) under hypoxic conditions $\left(1 \% \mathrm{O}_{2}, 94 \% \mathrm{~N}_{2}\right.$ and $5 \% \mathrm{CO}_{2}$ at $\left.37{ }^{\circ} \mathrm{C}\right)$ in the multi-gas incubator (BL-42MD; JUJI field Inc., Tokyo, Japan) for $10 \mathrm{~min}$ (OGD). Then, the cells were cultured with the highglucose DMEM under normoxic conditions ( $95 \%$ air and $5 \% \mathrm{CO}_{2}$ at $37^{\circ} \mathrm{C}$ ) for $5 \mathrm{~min}(\mathrm{R})$. Recombinant canstatin, PBS, gp91 ds-tat or tempol were treated throughout the experiment. Control cells were cultured in high-glucose-containing DMEM under normoxic conditions. After the OGD/R stimulation, the cells were used for lucigenin assay or DCF-DA staining.

\subsection{Lucigenin Assay}

To assess the activity of NOX in NRCMs, a lucigenin assay was performed as described previously [32]. Total cell lysates were harvested by lysis buffer (Nacalai tesque). Phosphate buffer $\left(200 \mu \mathrm{L}: 50 \mathrm{mM} \mathrm{NaH}_{2} \mathrm{PO}_{4}\right.$ and $\mathrm{NaHPO}_{4}, 1$ mM EGTA and $150 \mathrm{mM}$ sucrose at $\left.\mathrm{pH} 7.0\right)$ containing lucigenin $(10 \mu \mathrm{M}), \mathrm{NADPH}(1 \mathrm{mM})$ and cell lysate $(20 \mu \mathrm{g})$ was poured into assay wells (96-well plates). Then, the chemiluminescence was continuously measured for 30 min at $37^{\circ} \mathrm{C}$ by a TriStar LB941 luminometer (Berthold, Bad, Wildbad, Germany). The chemiluminescence of relative light units per second (RLU/s) was obtained every $10 \mathrm{~s}$, and the results were calculated as area under the curve.

\subsection{DCF-DA Staining}

To evaluate intracellular ROS production in NRCMs, DCF-DA staining was performed as described previously [31]. The cells were incubated with DCF-DA $(10 \mu \mathrm{M}$; Invitrogen, Carlsbad, CA, USA) for $30 \mathrm{~min}$ at $37^{\circ} \mathrm{C}$. Fluorescence images were obtained by a microscope digital camera (DP-74; OLYMPUS, Tokyo, Japan)-equipped fluorescent microscope (BX-51; OLYMPUS). The fluorescent intensity was measured by Image J software (Version 1.52a; National Institutes of Health, Bethesda, MD, USA).

\subsection{Measurement of $\left[\mathrm{Ca}^{2+}\right]_{i}$ in NRCMs}

$\left[\mathrm{Ca}^{2+}\right]_{\mathrm{i}}$ in NRCMs was measured by using Fura-2 acetoxymethyl ester (AM) (Nacalai tesque) as described previously [15]. The cells were incubated with normal 4-(2-Hydroxyethyl) -1-piperazineethanesulfonic acid (HEPES)-Tyrode solution $\left(1.8 \mathrm{mM} \mathrm{CaCl}_{2}, 143 \mathrm{mM} \mathrm{NaCl}\right.$, $5.4 \mathrm{mM} \mathrm{KCl}, 0.33 \mathrm{mM} \mathrm{NaH} \mathrm{PO}_{4}, 0.5 \mathrm{mM} \mathrm{MgCl} 26 \mathrm{H}_{2} \mathrm{O}, 5.5 \mathrm{mM}$ Glucose and $5 \mathrm{mM}$ HEPES) with Fura-2 AM $(5 \mu \mathrm{M})$ for $30 \mathrm{~min}$ at $37^{\circ} \mathrm{C}$, and then incubated with Fura-2 AM-free normal HEPES-Tyrode solution for $30 \mathrm{~min}$ at $37^{\circ} \mathrm{C}$. Then, the cells were alternately excited 
at 340 and $380 \mathrm{~nm}$ by using a rotating filter wheel, and the fluorescence (emissions at $500 \mathrm{~nm}$ ) of Fura-2AM was obtained by a dual-wavelength fluorometer (CAM-230; Japan Spectroscopic Co, Ltd., Tokyo, Japan). NRCMs were stimulated with $\mathrm{H}_{2} \mathrm{O}_{2}(100 \mu \mathrm{M}, 30 \mathrm{~min})$ after pretreatment with PBS, canstatin $(250 \mathrm{ng} / \mathrm{mL})$ or tempol $(1 \mathrm{mM}$; positive control) for 5 min. The F340/F380 ratio (F) was calculated and normalized by the basal fluorescence $\left(\mathrm{F}_{0}\right)$ at $30 \mathrm{~s}$, obtained before $\mathrm{H}_{2} \mathrm{O}_{2}$ treatment.

\subsection{Statistical Analysis}

Data are presented as mean \pm standard error of the mean (S.E.M.). In two group comparisons, statistical analyses were performed by unpaired two-tailed Student's $t$-test (Figure 2B). In the multi-group comparison, statistical analyses were performed by one-way ANOVA followed by Bonferroni's post hoc test (Figures 4A,B, 5 and 6B). A value of $p<0.05$ was considered statistically significant.

\section{Conclusions}

Our data suggest that canstatin is preventive against I/R-induced ventricular arrhythmia, perhaps in part through the suppression of ROS production and the subsequent $\left[\mathrm{Ca}^{2+}\right]_{i}$ rise in cardiomyocytes. It is expected that canstatin contributes to the development of a novel therapeutic strategy to suppress I/R-induced ventricular arrhythmia in AMI patients.

Author Contributions: Conceptualization, A.S., M.O. and H.Y.; investigation, A.S., Y.S. and M.O.; resources, M.O., K.O. and H.Y.; data curation, A.S., Y.S., M.O. and H.Y.; writing-original draft preparation, A.S.; writing-review and editing, M.O. and H.Y.; visualization, M.O.; supervision, M.O., K.O. and H.Y.; project administration, M.O., K.O. and H.Y.; funding acquisition, A.S. All authors have read and agreed to the published version of the manuscript.

Funding: This work was supported by Grant in Aid for Japan society for the Promotion of Science Research Fellow Grant (JSPS KAKENHI Grant Number 18J20623).

Institutional Review Board Statement: The study was conducted according to the guidelines of the Declaration of Helsinki, and approved by the President of Kitasato University through the judgement of Institutional Animal Care and Use Committee of Kitasato University (Approval No. 18-019 (18 June 2018), 19-126 (29 August 2019)).

Informed Consent Statement: Not applicable.

Data Availability Statement: The datasets presented in this study are available from the corresponding author upon reasonable request.

Conflicts of Interest: The authors declare no conflict of interest.

\section{References}

1. Palasubramaniam, J.; Wang, X.; Peter, K. Myocardial infarction-From atherosclerosis to thrombosis: Uncovering new diagnostic and therapeutic approaches. Arterioscler. Thromb. Vasc. Biol. 2019, 39, E176-E185. [CrossRef]

2. Hausenloy, D.J.; Yellon, D.M. Myocardial ischemia-reperfusion injury: A neglected therapeutic target. J. Clin. Investig. 2013, 123, 92-100. [CrossRef] [PubMed]

3. Neri, M.; Riezzo, I.; Pascale, N.; Pomara, C.; Turillazzi, E. Ischemia/reperfusion injury following acute myocardial infarction: A critical issue for clinicians and forensic pathologists. Mediat. Inflamm. 2017, 2017, 7018393. [CrossRef] [PubMed]

4. Yang, C.F. Clinical manifestations and basic mechanisms of myocardial ischemia/reperfusion injury. Tzu Chi Med. J. 2018, 30, 209-215. [CrossRef] [PubMed]

5. Granger, D.N.; Kvietys, P.R. Reperfusion injury and reactive oxygen species: The evolution of a concept. Redox Biol. 2015, 6, 524-551. [CrossRef] [PubMed]

6. Sovari, A.A. Cellular and molecular mechanisms of arrhythmia by oxidative stress. Cardiol. Res. Pract. 2016, 2016, 9656078. [CrossRef] [PubMed]

7. Kistamás, K.; Veress, R.; Horváth, B.; Bányász, T.; Nánási, P.P.; Eisner, D.A. Calcium handling defects and cardiac arrhythmia syndromes. Front. Pharmacol. 2020, 11, 72. [CrossRef]

8. Landstrom, A.P.; Dobrev, D.; Wehrens, X.H.T. Calcium signaling and cardiac arrhythmias. Circ. Res. 2017, 120, 1969-1993. [CrossRef] 
9. Priori, S.G.; Blomström-Lundqvist, C.; Mazzanti, A.; Bloma, N.; Borggrefe, M.; Camm, J.; Elliott, P.M.; Fitzsimons, D.; Hatala, R.; Hindricks, G.; et al. 2015 ESC Guidelines for the management of patients with ventricular arrhythmias and the prevention of sudden cardiac death: The task force for the management of patients with ventricular arrhythmias and the prevention of sudden cardiac death of the Europe. Europace 2015, 17, 1601-1687.

10. Brogden, R.N.; Benfield, P. Verapamil: A review of its pharmacological properties and therapeutic use in coronary artery disease. Drugs 1996, 51, 792-819. [CrossRef]

11. Kamphaus, G.D.; Colorado, P.C.; Panka, D.J.; Hopfer, H.; Ramchandran, R.; Torre, A.; Maeshima, Y.; Mier, J.W.; Sukhatme, V.P.; Kalluri, R. Canstatin, a novel matrix-derived inhibitor of angiogenesis and tumor growth. J. Biol. Chem. 2000, 275, 1209-1215. [CrossRef] [PubMed]

12. Sugiyama, A.; Mitsui, A.; Okada, M.; Yamawaki, H. Cathepsin S degrades arresten and canstatin in infarcted area after myocardial infarction in rats. J. Vet. Med. Sci. 2019, 81, 522-531. [CrossRef] [PubMed]

13. Sugiyama, A.; Okada, M.; Yamawaki, H. Pathophysiological roles of canstatin on myofibroblasts after myocardial infarction in rats. Eur. J. Pharmacol. 2017, 807, 32-43. [CrossRef] [PubMed]

14. Imoto, K.; Hirakawa, M.; Okada, M.; Yamawaki, H. Canstatin modulates L-type calcium channel activity in rat ventricular cardiomyocytes. Biochem. Biophys. Res. Commun. 2018, 499, 954-959. [CrossRef] [PubMed]

15. Sugiyama, A.; Okada, M.; Yamawaki, H. Canstatin suppresses isoproterenol-induced cardiac hypertrophy through inhibition of calcineurin/nuclear factor of activated T-cells pathway in rats. Eur. J. Pharmacol. 2020, 871, 172849. [CrossRef] [PubMed]

16. Jeong, E.M.; Liu, M.; Sturdy, M.; Gao, G.; Varghese, S.T.; Sovari, A.A.; Dudley, S.C., Jr. Metabolic stress, reactive oxygen species, and arrhythmia. J. Mol. Cell. Cardiol. 2012, 52, 454-463. [CrossRef] [PubMed]

17. Sedighi, M.; Nazari, A.; Faghihi, M.; Rafieian-Kopaei, M.; Karimi, A.; Moghimian, M.; Mozaffarpur, S.A.; Rashidipour, M.; Namdari, M.; Cheraghi, M.; et al. Protective effects of cinnamon bark extract against ischemia-reperfusion injury and arrhythmias in rat. Phyther. Res. 2018, 32, 1983-1991. [CrossRef]

18. Dodo, K.; Shimizu, T.; Sasamori, J.; Aihara, K.; Terayama, N.; Nakao, S.; Iuchi, K.; Takahashi, M.; Sodeoka, M. Indolylmaleimide derivative IM-17 shows cardioprotective effects in ischemia-reperfusion injury. ACS Med. Chem. Lett. 2018, 9, 182-187. [CrossRef]

19. Lu, H.R.; Yang, P.; Remeysen, P.; Saels, A.; Dai, D.Z.; De Clerck, F. Ischemia/reperfusion-induced arrhythmias in anaesthetized rats: A role of $\mathrm{Na}^{+}$and $\mathrm{Ca}^{2+}$ influx. Eur. J. Pharmacol. 1999, 365, 233-239. [CrossRef]

20. Gorenek, B.; Blomström Lundqvist, C.; Brugada Terradellas, J.; Camm, A.J.; Hindricks, G.; Huber, K.; Kirchhof, P.; Kuck, K.H.; Kudaiberdieva, G.; Lin, T.; et al. Cardiac arrhythmias in acute coronary syndromes: Position paper from the joint EHRA, ACCA, and EAPCI task force. EuroIntervention 2015, 10, 1095-1108. [CrossRef]

21. Magnon, C.; Galaup, A.; Mullan, B.; Rouffiac, V.; Bidart, J.M.; Griscelli, F.; Opolon, P.; Perricaudet, M. Canstatin acts on endothelial and tumor cells via mitochondrial damage initiated through interaction with $\alpha_{\mathrm{v}} \beta_{3}$ and $\alpha_{\mathrm{v}} \beta_{5}$ integrins. Cancer Res. 2005, 65, 4353-4361. [CrossRef] [PubMed]

22. Honoré, S.; Kovacic, H.; Pichard, V.; Briand, C.; Rognoni, J.B. $\alpha_{2} \beta_{1}$-Integrin signaling by itself controls G1/S transition in a human adenocarcinoma cell line (Caco-2): Implication of NADPH oxidase-dependent production of ROS. Exp. Cell Res. 2003, $285,59-71$. [CrossRef]

23. Kim, E.Y.; Roshanravan, H.; Dryer, S.E. Syndecan-4 ectodomain evokes mobilization of podocyte TRPC6 channels and their associated pathways: An essential role for integrin signaling. Biochim. Biophys. Acta. 2015, 1853, 2610-2620. [CrossRef] [PubMed]

24. Cowden Dahl, K.D.; Robertson, S.E.; Weaver, V.M.; Simon, M.C. Hypoxia-inducible factor regulates $\alpha_{\mathrm{v}} \beta_{3}$ integrin cell surface expression. Mol. Biol. Cell 2005, 16, 1901-1912. [CrossRef] [PubMed]

25. Skuli, N.; Monferran, S.; Delmas, C.; Favre, G.; Bonnet, J.; Toulas, C.; Moyal, E.C.J. $\alpha_{v} \beta_{3} / \alpha_{v} \beta_{5}$ Integrins-FAK-RhoB: A novel pathway for hypoxia regulation in glioblastoma. Cancer Res. 2009, 69, 3308-3316. [CrossRef] [PubMed]

26. Kanazawa, H.; Imoto, K.; Okada, M.; Yamawaki, H. Canstatin inhibits hypoxia-induced apoptosis through activation of integrin/focal adhesion kinase/Akt signaling pathway in H9c2 cardiomyoblasts. PLoS ONE 2017, 12, e0173051. [CrossRef]

27. Wu, X.; Mogford, J.E.; Platts, S.H.; Davis, G.E.; Meininger, G.A.; Davis, M.J. Modulation of calcium current in arteriolar smooth muscle by $\alpha_{\mathrm{v}} \beta_{3}$ and $\alpha_{5} \beta_{1}$ integrin ligands. J. Cell Biol. 1998, 143, 241-252. [CrossRef]

28. Okada, H.; Lai, N.C.; Kawaraguchi, Y.; Liao, P.; Copps, J.; Sugano, Y.; Okada-Maeda, S.; Banerjee, I.; Schilling, J.M.; Gingras, A.R.; et al. Integrins protect cardiomyocytes from ischemia/reperfusion injury. J. Clin. Investig. 2013, 123, 4294-4308. [CrossRef]

29. Page, R.L.; Joglar, J.A.; Caldwell, M.A.; Calkins, H.; Conti, J.B.; Deal, B.J.; Estes, N.A.M.; Field, M.E.; Goldberger, Z.D.; Hammill, S.C.; et al. 2015 ACC/AHA/HRS guideline for the management of adult patients with supraventricular tachycardia: A report of the American College of Cardiology / American Heart Association Task Force on Clinical Practice Guidelines and the Heart Rhythm Society. Circulation 2016, 133, e506-e574. [CrossRef]

30. Sugiyama, A.; Ito, R.; Okada, M.; Yamawaki, H. Long-term administration of recombinant canstatin prevents adverse cardiac remodeling after myocardial infarction. Sci. Rep. 2020, 10, 12881. [CrossRef]

31. Yasuda, J.; Okada, M.; Yamawaki, H. Protective effect of T3 peptide, an active fragment of tumstatin, against ischemia/reperfusion injury in rat heart. J. Pharmacol. Sci. 2019, 139, 193-200. [CrossRef] [PubMed]

32. Mukohda, M.; Morita, T.; Okada, M.; Hara, Y.; Yamawaki, H. Long-term methylglyoxal treatment impairs smooth muscle contractility in organ-cultured rat mesenteric artery. Pharmacol. Res. 2012, 65, 91-99. [CrossRef] [PubMed] 